\title{
Intraoperative Detection of Cold Agglutinins During Cardiopulmonary Bypass in a Child
}

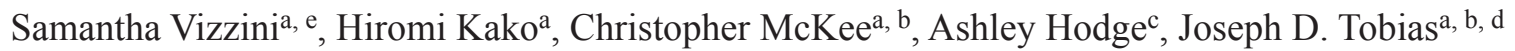

\begin{abstract}
Cold agglutinins are auto-antibodies, usually of the $\operatorname{IgM}$ class, that are present in low titers in the blood of normal individuals. They are generally of no clinical significance in healthy patients because they are active only at extremely low temperatures (less than $10^{\circ} \mathrm{C}$ ). However, when present in high titers, during periods of hypothermia, they may have clinical impact. We present a child presenting for surgery for congenital heart disease, in whom blood agglutination was noted during hypothermia while on cardiopulmonary bypass (CPB). The history of cold agglutinin disease is presented, typical clinical manifestations are discussed, and options for perioperative care including the conduct of CPB are presented.
\end{abstract}

Keywords: Cold agglutinins; Cardiopulmonary bypass; Congenital cardiac disease

\section{Introduction}

Cold agglutinins are auto-antibodies, usually of the IgM class, that are present in low titers in the blood of normal individuals. They are of no clinical significance in healthy patients because they are active only at extremely low temperatures (less than $10^{\circ} \mathrm{C}$ ). However, these antibodies can be found in higher titers, most commonly related to antecedent viral or mycoplasma infections $[1,2]$. At these higher titers, the red blood

Manuscript accepted for publication January 29, 2015

aDepartment of Anesthesiology \& Pain Medicine, Nationwide Children's Hospital, Columbus, $\mathrm{OH}$, USA

${ }^{b}$ Department of Anesthesiology \& Pain Medicine, The Ohio State University College of Medicine, Columbus, OH, USA

${ }^{\mathrm{c} C a r d i o v a s c u l a r}$ Perfusion Services and the Heart Center, Nationwide Children's Hospital and the Ohio State University, Columbus, OH, USA

dDepartment of Pediatrics, The Ohio State University College of Medicine, Columbus, OH, USA

${ }^{\mathrm{e}}$ Corresponding Author: Samantha Vizzini, Department of Anesthesiology \& Pain Medicine, Nationwide Children's Hospital, 700 Children's Drive, Columbus, OH 43205, USA.

Email: Samantha.Vizzini@Nationwidechildrens.org

doi: http://dx.doi.org/10.14740/jmc2034w cells (RBCs) may react at a broader range of temperatures and may result in clinical manifestations at $30-37{ }^{\circ} \mathrm{C}$. We present a child presenting for surgery for congenital heart disease (CHD), in whom blood agglutination was noted during hypothermia while on cardiopulmonary bypass (CPB). The history of cold agglutinin disease (CAD) is presented, typical clinical manifestations are discussed, and options for perioperative care including the conduct of $\mathrm{CPB}$ are presented.

\section{Case Report}

IRB approval is not required for single patient case reports at Nationwide Children's Hospital. A 12-year-old boy with a history of tetralogy of Fallot status-post repair at 4 months of age with a trans-annular patch of the right ventricular outflow tract presented for pulmonary valve replacement. Preoperative findings included severe right ventricular dilation and severe pulmonary regurgitation. A peripheral intravenous catheter was placed in the preoperative area and anxiolysis was achieved with intravenous midazolam and fentanyl. The patient was then transported to the operating room where standard Ameri-

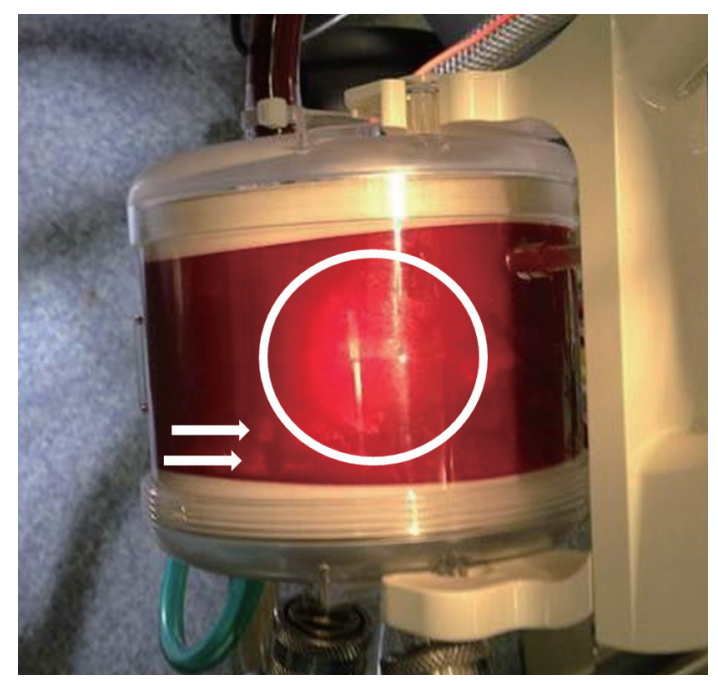

Figure 1. Agglutination in the venous reservoir and oxygenator during hypothermia and cardiopulmonary bypass. The agglutination can be seen as a white aggregate forming in the reservoir (circle and arrows). 
can Society of Anesthesiologists' monitors were applied. Prior to anesthetic induction, bilateral paravertebral blocks were placed in the sitting position with a total of $20 \mathrm{~mL}$ of $0.5 \%$ ropivacaine. The patient tolerated the procedure well and general anesthesia was subsequently induced followed by endotracheal intubation. A right internal jugular triple-lumen catheter was placed with ultrasound guidance as well as a right radial arterial line. The patient remained stable throughout both of these procedures. A time-out was performed and the surgical incision was made with median sternotomy. After adequate dissection and visualization was obtained, cannulation sutures were placed in the aorta and inferior and superior vena cava. A heparin loading dose of $400 \mathrm{IU} / \mathrm{kg}$ was administered and cannulation for CPB was performed. After adequate anticoagulation was established with a target activated clotting time (ACT) of $480 \mathrm{~s}$ with the $\mathrm{HMS}^{\circledR}$ Heparin Management System (Medtronic Inc., Minneapolis, MN, USA), CPB was initiated and full flow was achieved. The patient was then cooled to 34 ${ }^{\circ} \mathrm{C}$. Twenty-four minutes after the initiation of cooling, the perfusionist alerted the surgeon for concerns of cold agglutination noted in the venous reservoir and oxygenator (Fig. 1). At that time, the decision was made to rewarm the patient to $36^{\circ} \mathrm{C}$ and increase the fraction of inspired oxygen $\left(\mathrm{FiO}_{2}\right)$ to $100 \%$. The patient remained stable throughout the procedure and neither pump flow nor pressures were altered by the reaction. After rewarming the patient, the agglutination reaction partially dissipated and the surgical repair was completed under normothermia. The patient was weaned from CPB. A cold agglutinin titer was sent after the termination of CPB; however, the results were non-diagnostic (see below). After completion of the procedure, the patient's trachea was extubated in the operating room and he was transported to the cardiothoracic intensive care unit (CTICU). The remainder of his postoperative course was uneventful and the patient was discharged home on postoperative day 4.

\section{Discussion}

Two forms of cold antibody autoimmune hemolytic anemia have been identified including Donath-Landsteiner hemolytic anemia (DLHA) and CAD. DLHA is an intravascular hemolytic anemia caused by a cold-reacting immunoglobulin of the $\mathrm{IgG}$ which is usually directed at either the P or I antigen on the RBC surface. Most cases are due to polyclonal IgG, although IgM-induced DLHA has been described [1-3]. In contrast to DLHA, CAD is always due to a cold-reacting IgM antibody.

Investigations into the etiology of these disorders began as early as 1865, when cases of hemoglobinuria following exposure to cold were identified. Although Donath and Landsteiner first characterized the causative antibody and later described the presence of these antibodies in humans in studies comparing human and primate blood, the association between these antibodies, cold agglutination, and hemolysis was not described until 1937 [4-6]. Sir John Dacie published "The haemolytic anaemias" in 1966 which described 16 cases of CAD [7]. Dacie noted that cold agglutinins could be identified in both healthy patients and those with symptoms. The differ- ence was the thermal amplitude of the cold agglutinins with healthy patients showing agglutination only at temperatures below $4{ }^{\circ} \mathrm{C}$ compared to symptomatic patients who agglutinated at temperatures as high as $37^{\circ} \mathrm{C}$.

$\mathrm{CAD}$ is a subtype of autoimmune hemolytic anemia which involves IgM antibodies which are active at cold temperatures and directed against surface antigens of RBCs. CAD may either be primary/idiopathic or secondary to another disease process such as lymphoma or infections including Mycoplasma pneumoniae. Typically, the idiopathic form presents in patients over the age of 50 with no reported cases in pediatric patients [1]. Patients may be asymptomatic or present with acrocyanosis, chest pain, abdominal pain, or Raynaud's phenomenon. Occasionally patients present with odynophagia when eating cold food.

The understanding of the pathophysiology of this disease has greatly improved in the past 20 years. The antibodies involved are generally low in titer and only active at extremely low temperatures in the majority of patients and therefore clinically insignificant. However, during cardiac surgery when cooling is required for cardiac and neurologic protection, significant problems may be noted even in patients with relatively low antibody titers. Antibodies bind to RBC membranes in the periphery where the temperature is low causing agglutination and activation of the complement system. Once the complement system is activated, C3 convertase cleaves $\mathrm{C} 3$ into $\mathrm{C} 3 \mathrm{a}$ and $\mathrm{C} 3 \mathrm{~b}$, which binds to $\mathrm{RBC}$ membranes and serves as a target for tissue macrophages and extravascular hemolysis [8]. As $\mathrm{RBCs}$ recirculate to the warmer core of the body, IgM dissociates from the RBCs and the agglutinated RBCs separate from each other. However, $\mathrm{C} 3 \mathrm{~b}$ remains on the surface of the $\mathrm{RBC}$ leading to sequestration and destruction in the liver leading to anemia, hematuria, mircrothrombi and in severe cases, circulatory collapse.

It is not standard practice to test specifically for these antibodies prior to cardiac surgery because they cannot be detected with standard antibody screening and the incidence of clinically significant titers is low. The specific test for CAD is a quantitative assay which is run only in specific reference laboratories. Stringent rules must be followed for collection and transport of the sample to the lab. Blood must be collected in warmed tubes and kept in a $37^{\circ} \mathrm{C}$ water bath. This allows the antibodies to dissociate from the RBCs and back into the plasma. Once the sample arrives at the hospital laboratory, it is allowed to clot at $37^{\circ} \mathrm{C}$ and then spun down to separate the serum from the RBCs. Only the serum is sent to the outside lab for antibody detection. Therefore if temperature regulations are not strictly followed, there will be no antibodies to detect in the serum as they will remain bound to the patient's RBCs. Antibody titers $\geq 1: 32$ are considered a positive result. In the past, with a positive antibody titer, thermal amplitudes were previously calculated to determine at what temperature agglutination would occur. Recently this appears to have fallen out of favor, and if laboratories obtain a positive result, a qualitative assay is performed to determine the type of immunoglobulin involved. Unfortunately, in our patient, it appears that these strict parameters for care of the blood test were not followed and as such, it is possible that a false negative test resulted. As 
Table 1. Previous Reports of Anesthesia for Patients With Cold Agglutinins

\begin{tabular}{ll}
\hline Authors and reference & Patient demographics \\
\hline Fischer et al [1] & $\begin{array}{l}\text { A 60-year-old male with unstable angina, hypertension, and hypercholesterolemia for urgent coronary artery } \\
\text { bypass grafting. }\end{array}$ \\
Kalra et al [13] & $\begin{array}{l}\text { A 38-year-old female with rheumatic heart disease with mitral stenosis and mitral regurgitation for mitral valve } \\
\text { replacement. }\end{array}$ \\
& $\begin{array}{l}\text { A 62-year-old male with long-standing, cold agglutinin disease, diabetes mellitus, ischemic heart disease with } \\
\text { previous coronary stenting, B-cell in remission, and OSA for an abdomino-peroneal excision of the rectum for a }\end{array}$ \\
Young et al [14] & $\begin{array}{l}\text { Duke's stage A low rectal carcinoma. } \\
\text { An 82-year-old female with worsening angina and decreased exercise tolerance, paroxysmal atrial fibrillation, } \\
\text { diabetes mellitus, and dyslipidemia for coronary artery bypass graft surgery. Routine preoperative antibody }\end{array}$ \\
screening for cross-matching revealed cold agglutinins. Further history revealed symptoms suggestive of cold \\
agglutinin disease.
\end{tabular}

our patient is clinically asymptomatic and does not appear to need further cardiac surgery, we do not plan to retest him at this time.

Clinical management of patients with CAD has previously consisted of cold avoidance, corticosteroid therapy, plasmapheresis, and even exchange transfusion. Given their invasive nature, techniques such as plasmapheresis or exchange transfusion, are only recommended when there is no option other than deep hypothermia for specific surgical procedures. In the past 30 years, there have been several advancements in the understanding of the pathology and immune basis for this disease leading to improvements in treatment options. Silberstein et al studied patients with lymphoma induced and idiopathic cold agglutinins and found a monoclonal defect in B-cell lymphocytes in both patient populations which has served as a target for immuno-modulating drug therapy in recent years [9]. His work has identified a specific cell line of B-cell lymphocytes which may allow specific therapy with rituximab, a chimeric monoclonal antibody against the protein $\mathrm{CD} 20$, which is primarily found on the surface of B-cell lymphocytes.

As occurred in our patient, there are several anecdotal reports of CAD being diagnosed intraoperatively with problems occurring being noted during hypothermia and CPB including intracoronary thrombosis, incomplete cardioplegia delivery, agglutination within the circuit, and high pressures in the CPB circuit [10-13]. Other authors have previously reported suggestions for the perioperative management during the care of patients with CAD (Table 1) [14-18]. When CAD follows an infectious etiology, elective and non-urgent procedures should be postponed as the antibody titer can be expected to decline over 4 - 8 weeks. In general, maintenance of normothermia is essential with forced air warming of the patient [16]. Such therapy may be instituted preoperatively when the patient is known to have CAD [19]. Additionally, intraoperative warming and humidification of inspired gases as well as intravenous fluids may be indicated. Irrigation fluids should also be warmed and any exposed organs may be wrapped in warm packs to prevent evaporative heat loss. Prevention of a cold agglutination reaction in cardiac surgical patients may require warming all fluids including the CPB circuit as well as the cardioplegia solution. In specific cases, warm cardioplegia may be required [9]. The patient's body temperature should be kept several degrees above the thermal amplitude of the antibody if that is known. Allogeneic blood products should be avoided if possible as the donor RBCs will be free of C3d fragments [8]. C3d is a degradation product of $\mathrm{C} 3 \mathrm{~b}$ that coats RBCs after an episode if agglutination and may provide some protection from further hemolysis.

\section{References}

1. Hayashi H, Yasutomi M, Hayashi T, Yuasa M, Kawakita A, Hata I, Tanizawa A, et al. Paroxysmal cold hemoglobinuria caused by an IgM-class Donath-Landsteiner antibody. Pediatr Int. 2013;55(5):664-666.

2. Berentsen S, Beiske K, Tjonnfjord GE. Primary chronic cold agglutinin disease: an update on pathogenesis, clinical features and therapy. Hematology. 2007;12(5):361370.

3. Berentsen S, Ulvestad E, Langholm R, Beiske K, HjorthHansen H, Ghanima W, Sorbo JH, et al. Primary chronic cold agglutinin disease: a population based clinical study of 86 patients. Haematologica. 2006;91(4):460-466.

4. Donath J, Landsteiner K. Ueber paroxysmale hamoglobinurie. Munchener Medizinische Wochenschrift. 1904;51:1590-1593.

5. Clough MC, Richter IM. A study of an auto-agglutinin occurring in human serum. Johns Hop Hosp Bull. 1918;29:86-93.

6. Rosenthal F, Corten M. Uber das Phanomen der Autohamagglutination und uber die Eigenscaften der Kalteha- 
magglutinine. Folia Haematol (Leipzig). 1937;58:64-90.

7. Dacie J. Auto-immune haemolytic anaemia (AIHA). Cold antibody syndromes I - Idiopathic types: Clinical Presentation and haematological and serological findings. In: Dacie J (editor). The Haemolytic Anaemias (Volume 3). London: Churchill-Livingstone; 1992:210-239.

8. Daaboul DG, Yuki K, Wesley MC, Dinardo JA. Anesthetic and cardiopulmonary bypass considerations for cardiac surgery in unique pediatric patient populations: sickle cell disease and cold agglutinin disease. World J Pediatr Congenit Heart Surg. 2011;2(3):364-370.

9. Silberstein LE, Robertson GA, Harris AC, Moreau L, Besa E, Nowell PC. Etiologic aspects of cold agglutinin disease: evidence for cytogenetically defined clones of lymphoid cells and the demonstration that an anti-Pr cold autoantibody is derived from a chromosomally aberrant B cell clone. Blood. 1986;67(6):1705-1709.

10. Park JV, Weiss CI. Cardiopulmonary bypass and myocardial protection: management problems in cardiac surgical patients with cold autoimmune disease. Anesth Analg. 1988;67(1):75-78.

11. Fischer GD, Claypoole V, Collard CD. Increased pressures in the retrograde blood cardioplegia line: an unusual presentation of cold agglutinins during cardiopulmonary bypass. Anesth Analg. 1997;84(2):454-456.

12. Dake SB, Johnston MF, Brueggeman P, Barner HB. Detection of cold hemagglutination in a blood cardioplegia unit before systemic cooling of a patient with un- suspected cold agglutinin disease. Ann Thorac Surg. 1989;47(6):914-915.

13. Kalra A, Singh K, Sahoo M, Mahant TS. Cold agglutinin disease detected during open heart surgery. Indian J Hematol Blood Transfus. 2014;30(1):62-63.

14. Young S, Haldane G. Major colorectal surgery in a patient with cold agglutinin disease. Anaesthesia. 2006;61(6):593-596.

15. Bratkovic K, Fahy C. Anesthesia for off-pump coronary artery surgery in a patient with cold agglutinin disease. J Cardiothorac Vasc Anesth. 2008;22(3):449-452.

16. Aoki A, Kay GL, Zubiate P, Ruggio J, Kay JH. Cardiac operation without hypothermia for the patient with cold agglutinin. Chest. 1993;104(5):1627-1629.

17. Beebe DS, Bergen L, Palahniuk RJ. Anesthetic management of a patient with severe cold agglutinin hemolytic anemia utilizing forced air warming. Anesth Analg. 1993;76(5):1144-1146.

18. Bracken CA, Gurkowski MA, Naples JJ, Smith H, Steinmann A, Samuel J, Strickler FR, et al. Case 6--1993. Cardiopulmonary bypass in two patients with previously undetected cold agglutinins. J Cardiothorac Vasc Anesth. 1993;7(6):743-749.

19. Perl T, Peichl LH, Reyntjens K, Deblaere I, Zaballos JM, Brauer A. Efficacy of a novel prewarming system in the prevention of perioperative hypothermia. A prospective, randomized, multicenter study. Minerva Anestesiol. 2014;80(4):436-443. 